DOI: 10.11606/issn.2238-3867.v17i2p430-435

sala preta

ppgac

Não estar é a única forma de presença de negros - e a culpa não é nossa

Not being is the only way of black people presence and it is not our fault

\title{
Stephanie Ribeiro
}

Stephanie Ribeiro Arquiteta, urbanista e escritora.

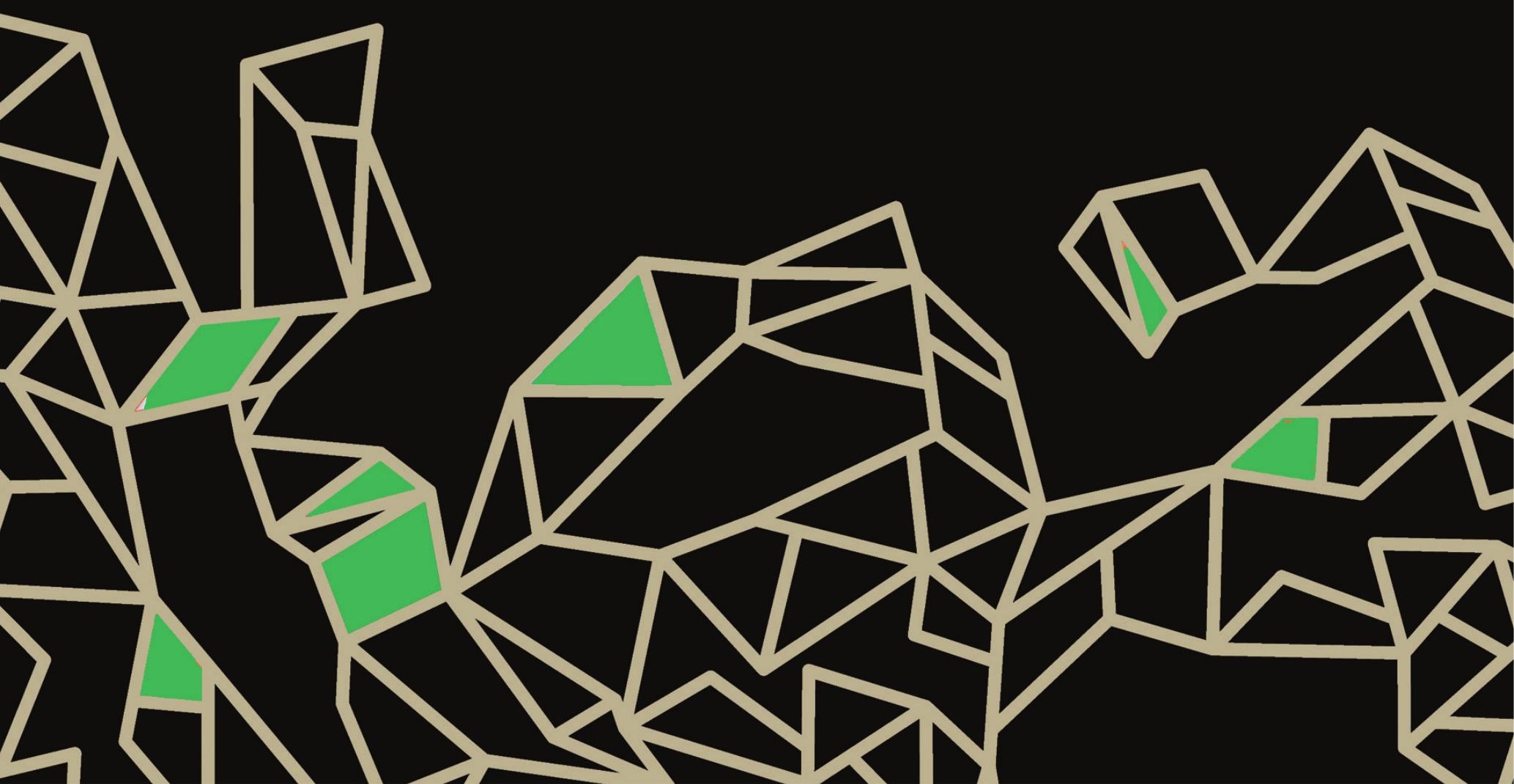


O espetáculo Branco: o cheiro do lírio e do formol, com roteiro assinado por Alexandre Dal Farra, diretor, juntamente com Janaina Leite - uma das atrizes da peça ao lado de André Capuano e Clayton Mariano -, foi uma grande surpresa para mim, e não há palavra rebuscada que justifique minha sensação após assistir a essa peça. Eu realmente não imaginava que a Mostra Internacional de Teatro de São Paulo (MITsp) e o Centro Cultural São Paulo (CCSP) destinariam verba e espaço para uma peça sobre branquitude caso realmente não tratasse desse tema de forma lúcida. Por mais que as intenções possam ter sido boas, foi falha, ao meu ver, a abordagem feita nesta obra.

Sendo assim, existe um erro de curadoria e roteiro em tal peça, exatamente por partir de uma visão que desconhece a forma como o conceito de raça atua nos sujeitos e na estrutura. É fato que falar de branquitude não é fácil, mas pessoas negras e brancas discutem esse tema de forma muito rica há muito tempo, em que constantemente negros debatem o impacto do racismo em suas vidas e, consequentemente, os privilégios da branquitude. Só que, exatamente por racismo ser estrutural, é mais fácil escutar e aplaudir um branco que aborda de forma rasa seus privilégios do que ceder espaço para negros falarem.

A peça Branco: o cheiro do lírio e do formol deixa evidente que não houve uma análise profunda sobre o tema que pretendia analisar. Arte é sim uma forma de questionar a sociedade, mas sabemos que nem sempre esses questionamentos são certeiros. Nesse espetáculo tudo caiu num verdadeiro "branco drama" que incomoda qualquer negro racialmente educado em relação a nossa estrutura racista. Se tirarmos toda a estética, os jogos de luz e até mesmo os cenários onde peles de animais vão sendo pisadas ao longo do espetáculo, o que sobraria?

\section{Um erro racista}

Há diálogos na peça que deixam brechas e associam o movimento negro a linchamento e atitudes ditatoriais. Não adianta então gritar "brancos são racistas", se nas entrelinhas o "bom branco brasileiro" escuta e assimila o que quer conforme a defesa dos seus privilégios. A forma como o roteiro é escrito é portanto um erro: um erro racista. E não teria como não ser, dado que para 
a desconstrução no campo artístico é necessário um trabalho coletivo de aprendizado e protagonismo, e a peça em questão contou apenas com roteiristas e diretores brancos.

Sendo assim, a composição do roteiro não fala, ao meu ver, sobre racismo e seus impactos negativos e segregacionistas, mas sim sobre as aflições do sujeito branco racista ao tentar provar que não é racista, sem perder seu local de privilégio e protagonismo, na dor. Uma das personagens brancas dessa narrativa relata ter sofrido assédio sexual de uma professora, em vários momentos a história do câncer do então pai do roteirista ganha destaque, e as várias personagens brancas com problemáticas dentro de suas subjetividades colaboraram para a ideia de que os brancos também sofrem.

Foi confundido sofrimento com racismo, que é estrutural e estruturante. Para o roteirista, essas narrativas eram a prova de que o branco precisa deixar algo morrer para rever seu racismo. Porém, dada a forma como as perguntas foram sendo feitas após o fim da peça num debate proposto pelos autores e atores, ficou nítido que as pessoas brancas entenderam: somos racistas, mas olha só como para mim branco também não é fácil - de forma que essas pessoas passaram a relatar suas dificuldades e até o fato de se sentirem negras. Só que racismo não é sobre sofrer ou se sentir negro, é sobre uma estrutura.

O branco brasileiro não entende que é branco, o que significa ser branco, qual o lugar que ele pode estar e está por ser branco, quais os privilégios de ser branco. Basta dizer para um branco brasileiro "Você é branco", que ele já se fecha e usa o famigerado "Somos todos frutos da miscigenação". Enquanto isso, negros continuam sem acesso ao ensino superior, continuam lotando presídios ou covas no cemitério, e apenas negros se importam, apenas negros falam sobre isso diariamente, apenas negros escrevem textos sobre negros em grandes veículos de mídia, apenas negros compartilham o sofrimento negro, apenas negros assistem à sua família sofrendo as consequências do racismo, apenas negros levam o RG para passear com o cachorro, pois têm medo da abordagem da polícia. E apenas brancos, na primeira crítica aos seus privilégios, mostram como não estão acostumados com a racialização, mostrando como acreditam que são a norma e que são universais. Em nenhum momento a peça tocou no fato que o branco não é o centro do 
universo, que existem subjetividades para além da vivenciada por quem detém os privilégios da branquitude.

Chega a me dar arrepios lembrar do câncer e morte do pai do roteirista, uma ficção que não fica clara, que vai sendo entrelaçada com as dificuldades de escrever esse roteiro quando seu pai está à beira da morte. Essa, para mim, é a prova de que no fundo se queria gerar empatia do espectador para com o sujeito branco, que só faz o mínimo ao pensar em racismo. No sentido literal, a peça é sobre o homem branco em seu privilégio, com o pai quase morrendo, que insiste em falar sobre racismo, mesmo sabendo que o movimento negro vai criticá-lo muito, e por isso escreve e reescreve a mesma peça. Esse sentido literal é obviamente passado pelos críticos e pelos próprios roteiristas para o metafórico.

\section{Arte é poder}

O problema é que dada a situação do país, a dupla interpretação não serve para falarmos de racismo. Não da forma que foi construída essa peça. Todo dia o racismo age na minha vida indicando inclusive onde devo ou não estar: espaços culturais são um exemplo de lugares onde negros estão sempre em minoria, assim como negros são afastados por uma série de fatores dos espaços de criação, pois além de não acreditarem no nosso intelecto, negam nossa capacidade de sermos artistas. Faz parte do processo racista identificar o intelecto como sendo uma característica natural do sujeito branco e entender que nós negros seríamos a emoção incapaz de raciocinar.

Arte é poder. Então a estrutura racista funciona muito bem que até mesmo quando brancos pretendem falar de seus privilégios, eles não conseguem contratar uma pessoa negra para nada nessa peça! Veja bem, o momento que mais me irritou foi saber que após o roteiro, escritor e atores escolhidos, tudo pensado, alguns "provocadores" negros foram chamados. Nós negros podemos ir além do papel de provocadores, e precisamos ir, para que de fato o racismo acabe um dia. Discordo que a peça deveria ter atores negros, acredito que se é para falar de branquitude faz sentido não ter negros no palco para a narrativa que propunham, mas acho cruel, racista e nocivo negros não serem chamadas para corroteirizar, fazer a curadoria dos materiais 
de referência, reler diálogos e falas. O termo "provocador" já é infeliz em si, mas a forma como o indivíduo negro foi usado - não como criador e capaz de interferir, mas sim como mero token caso alguém perguntasse se houve participação negra - é ainda pior.

Uma das principais formas de a branquitude rever seus conceitos em relação aos próprios privilégios é repensar, porque só compartilham seus bens entre si. Talvez, quando um dos "provocadores" disse "nós queremos as suas terras", alguns dos que detinham espaço de poder na própria peça não entenderam ou fingiram não entender. Pois é óbvio: nós precisamos ter salários, ter prêmios APCA, ter diplomas de grandes universidades, dirigir espetáculos relevantes, viver da própria arte e talento; e para isso terá que se abrir espaço para negros, mesmo que seja em peças que só brancos subam ao palco. Se a curadoria da MITsp e do CCSP não pensou nisso, veja que o erro é a prova de que o racismo é uma estrutura, age de forma muito sagaz para que negros continuem sendo marginalizados e subjugados.

Negros são vistos como "os outros", e eu, mulher negra, sou o outro do outro:

Mulheres brancas têm um status oscilante, enquanto um mesmo homem e outro; Homens negros exercem a função de oponentes dos homens brancos, por serem potenciais concorrentes na conquista das mulheres brancas, são homens, mas não brancos; Mulheres negras, entretanto, não são nem brancas, nem homens, e exercem uma função de "outro" do outro. (KILOMBA, 2008, p. 124, tradução minha)

Por fim, eu, o outro do outro, já quando o debate acontecia, uma moça branca disse olhando para mim, percebendo meu incômodo: "eu gostei da peça". Se elas e os roteiristas soubessem como a subjetividade negra é negada, entenderiam que, antes de gostar ou não de algo, negros precisam superar a barreira do negro chegando antes de si mesmo. A subjetividade do homem branco evidenciada em peça não revoluciona a estrutura em que minha subjetividade é negada de forma que se eu não gosto da peça, na verdade eu não entendo de arte.

O problema somos nós negros, os outros, enquanto o branco é o universal, o humanos e o capaz. Capaz de ser chamado de gênio até quando o 
branco se propõe falar sobre branquitude e racismo, deixando claro que não estar é a única forma de presença e humanidade negra.

\section{Referências bibliográficas}

KILOMBA, G. Plantation memories: episodes of everyday racism. Münster: Unrast, 2008.

Recebido em 16/10/2017

Aprovado em 23/10/2017

Publicado em 26/12/2017 